\title{
What Has Health Technology Assessment Ever Done for Us?
}

\section{Olga Löblová}

\section{Accepted for publication in Journal of Health Services Research \& Policy on 21 July 2017}

\begin{abstract}
Health technology assessment (HTA) has, in the past three decades, become a well-established part of coverage decisions in many countries. Despite this, very little is known about HTA's impact on health systems. Few studies evaluate the benefits of HTA for health outcomes, access to care or public budgets. In contrast, HTA has relatively clear upfront costs, which could potentially discourage policy-makers from institutionalizing HTA, especially in resource-tight contexts. It may be premature, though, to dismiss the policy altogether: its less tangible modernizing goals are still significant.
\end{abstract}

\section{Introduction}

Health technology assessment (HTA) has been one of the most popular policy tools of health care reimbursement, pricing and purchasing of the past thirty years. With the aim of informing coverage decisions by means of multidisciplinary evaluation of evidence, HTA has the backing of a large epistemic community. Public and private consultancies spread the message of HTA around the world $(1,2)$, as do international actors such as the World Health Organization (3), the World Bank (4) and the European Union (5), and international professional networks such as HTAi, ISPOR, RedETSA, HTAsiaLink and EUnetHTA (6).

Indeed, many governments have been seduced by HTA's promise: to improve allocation of resources in health care. Since the late 1980s, most of Western Europe as well as Australia, New Zealand, Canada and several US payer organizations have established dedicated HTA agencies. Some Asian (e.g. Taiwan), 
Latin American (e.g. Brazil) and Central and Eastern European (e.g. Poland) countries followed in the early 2000s. Other countries, however, have been more hesitant to institutionalize HTA bodies. This piece explores what health technology assessment has to offer to decision-makers of countries without institutionalized HTA, especially in low and middle resource contexts.

\section{Vague benefits}

Health economists agree that HTA is especially important in resource-tight contexts because opportunity costs of misdirected resources are higher, in relative terms, than in rich economies $(7,8)$. This is a convincing claim. However, empirical evidence of the impact of HTA on either health outcomes or spending, the end goals of HTA, is scarce.

Policy evaluation of HTA is practically non-existent (9-11). A 2008 review found that only four published studies assessed the impact of HTA on health outcomes or spending (12). Most studies focus on outputs of HTA agencies (e.g. number of HTA reports produced) and the extent to which conclusions of HTA reports are followed by decision-makers (10) - leading an observer to conclude that "the available knowledge to assess the effectiveness of HTA is just a bunch of 'case series' and 'case reports', with little external validity and usually surrogate outcomes" (13). Indeed, we know next to nothing about HTA's impact on health outcomes (9). An Austrian study, one of the most comprehensive country-level evaluations to date, excludes health outcomes "due to methodological limitations" (14). Similarly, a recent report on the United Kingdom's HTA program found that HTA has had an impact on patients' care, but it did not assess outcomes (15). Improved access to care as a result of institutionalized HTA is not explicitly mentioned in any reviews (9), except for an industry-commissioned report (16). Finally, evaluations of economic impact are mixed. An early Canadian study found projected annual savings between $\$ 16$ and $\$ 27$ million $(17,18)$; the Austrian analysis concludes that HTA recommendations had led to a "significant" reduction in expenditure, but deems precise monetary quantification impossible 
$(14,19)$. Another review, however, notes that while HTA's effects on spending are unclear, the guidance of the United Kingdom's NICE has led to an increase in spending, rather than decrease (10). The immediate and medium-term budgetary consequences of establishing an HTA body in low-resource contexts, have not been investigated by any study in Hailey and colleagues' recent review (9).

In short, the empirical benefits of HTA are at present unclear. We know little about how HTA affects patients' health and access to care, and little about what it does to public budgets.

\section{Clear costs}

For a field with "assessment" in its name, the absence of empirical evaluation is surprising. Policy evaluation is a complex exercise, in this case further complicated by the lack of a uniform recipe for design and implementation of HTA processes (or, for that matter, consensus on HTA methodology) across countries. The real-world variation might explain why much of the HTA literature focuses on the "uptake" of HTA by decision-makers - the tacit assumption being that impact can only be measured under ideal conditions, where expertise reigns unhindered by politics. However, this is of little relevance to policy-makers looking for real-world success stories and lesson-drawing opportunities from other countries' experience with HTA.

The upfront costs, on the other hand, are relatively clear. Setting up an HTA body is not cheap: German IQWiG has an annual budget of approximately EUR 13 million (USD 14.8 million); Polish AOTMiT EUR 3.5 million; Belgian KCE EUR 10 million (20). To compare: KCE's budget represents about 30\% of the annual budget of a large university hospital in the Czech Republic (21). Further, there is a concern that HTA might in effect increase expenditure. An independent with decision-making powers HTA agency may prioritize evidence of cost-effectiveness or relative effectiveness over budget impact (more than the ministry of health or payers), leading to coverage of technologies that would have otherwise been denied reimbursement. Even a purely advisory body may make implicit rationing difficult for decision- 
makers, and bring unwanted attention to the lack of funds or inefficiencies in the health system. Likewise, introducing a new institution may destabilize the practice of delaying reimbursement decisions, common to some resource-tight countries. While all of these potentialities may ultimately be good news for patients, they are unlikely to be immediately attractive to policy-makers focused on health gains and costcontainment in the short term.

HTA is also not easy to implement: creating new institutions and adjusting pricing and reimbursement processes requires more than a couple of days' worth of legislative effort. In addition, many low-resource countries first need to train sufficient numbers of HTA experts. Both the financial costs and the effort might well be worth it - if policy-makers can be convinced HTA delivers on its promises.

\section{Modernizing mission}

Beyond the uncertain effects of HTA on health systems, an additional promise of HTA concerns its consequences for decision-making styles and cultures and for social justice. Some evaluations suggest, in line with Weiss' "Enlightenment" conceptualization of the knowledge-policy relationship (22), that HTA acts by changing mindsets rather than immediately determining actions $(12,14)$. Institutionalized HTA marks a departure from the opaque and arbitrary pricing and reimbursement practices customary in many countries. It is a departure underpinned by normative and epistemic beliefs in the superiority of evidencebased decisions, independence of expert input, transparency and inclusiveness of social actors ("stakeholder dialogue") (23). These are linked to the rise of evidence-based medicine (24) and perhaps more generally "good governance" and the trend of expert decision-making (25). None of these principles guarantee improving the quality, equity or sustainability of health systems. Whether rationalcomprehensive policy-making leads to better outcomes than "muddling through" incremental adjustments, has been a debate for decades (26), and good governance probably attracts more critics than 
advocates (27). However, for some decision-makers, a focus on evidence, transparency and inclusiveness may represent values in themselves - worth the budget of a provincial hospital.

An equally compelling promise of HTA (and equally difficult to quantify) is connected to its potential of increasing procedural justice in allocative decisions (28). Here, too, much depends on the details of the institutional setup of HTA - Daniels and van der Wilt, for instance, argue that a deliberative element is necessary for HTA to produce legitimate and fair decisions (29). However, HTA's proposal to reduce arbitrary decisions touches directly on health systems' ambitions of equity and societies' desires for fair institutions.

For many low- and middle-income countries today, the combination of theoretical and normative arguments for HTA offers a powerful modernizing vision for their health systems. For example, a 2014 World Health Assembly resolution mentions both efficiency concerns and principles of evidence-based policy-making as reasons for encouraging HTA, especially in low-income countries (30). This modernizing potential makes HTA hard to dismiss, despite a surprising absence of evidence of its effects after more than two decades of existence. Other policies, from international reference pricing to risksharing agreements or implicit rationing, may be easier to implement and fare better at containing costs, but none offer as complex a promise as HTA. This makes HTA currently a policy without direct alternatives, potentially attractive to policy-makers around the world for many different reasons.

\section{References}

1. Ecorys. Ecorys to assist health systems in Uttar Pradesh, India [Internet]. Ecorys.com. [cited 2016 Mar 27]. Available from: http://www.ecorys.com/news/ecorys-assist-health-systems-uttar-pradesh-india

2. Lopert R, Ruiz F, Chalkidou K. Applying rapid "de-facto" HTA in resource-limited settings: experience from Romania. Health Policy. Elsevier Ireland Ltd; 2013 Oct;112(3):202-8. 
3. Panamerican Health Organization. 28th PAN AMERICAN SANITARY CONFERENCE. Resolution CSP28R9: Health Technology Assessment and Incorporation into Health Systems. 2012. p. $17-21$.

4. Banta D, Jonsson E. History of HTA: Introduction. Int J Technol Assess Health Care. 2009;25 Suppl 1:1-6.

5. European Commission. Directorate-General Health \& Consumer Protection. Communication $\operatorname{COM}(2014) 215$ final from the Commission on effective, accessible and resilient health systems [Internet]. 2014. Available from: http://ec.europa.eu/health/healthcare/docs/com2014_215_final_en.pdf

6. HTAi - Health Technology Assessment international, www.HTAi.org; ISPOR - International Society For Pharmacoeconomics and Outcomes Research, www.ispor.org; RedETSA - Health Technology Assessment Network of the Americas, www.redetsa.org; HTAsiaLink - collaboration between Asian HTA agencies, www.htaasialink.org; and EUnetHTA - European network for Health Technology Assessment, www.eunethta.eu

7. Moran V, Fidler A. Health technology assessment in Europe: Communicating and applying lessons learned from high-income countries to middle-income countries. J Manag Mark Healthc. 2010;3(2):141-9.

8. Kaló Z, Gheorghe A, Huic M, Csanádi M, Kristensen FB. HTA Implementation Roadmap in Central and Eastern European Countries. Health Econ. 2016 Feb 1;25:179-92.

9. Hailey D, Werkö S, Rosén M, Macpherson K, Myles S, Gallegos Rivero V, et al. Influence of Health Technology Assessment and Its Measurement. Int J Technol Assess Health Care. 2016;32(6):37684.

10. Sorenson C, Chalkidou K. Reflections on the evolution of health technology assessment in Europe. Health Econ Policy Law. 2012;7(1):25-45.

11. Oortwijn W, Broos P, Vondeling H, Banta D, Todorova L. Mapping of health technology assessment in selected countries. Int J Technol Assess Health Care. 2013 Oct;29(4):424-34.

12. Gerhardus A, Dorendorf E, Røttingen J-A, Santamera AS. What are the effects of HTA reports on the health system? Evidence from the research literature. In: Garrido MV, Kristensen FB, Nielsen CP, Busse R, editors. HEALTH TECHNOLOGY ASSESSMENT AND HEALTH POLICY-MAKING IN EUROPE. Copenhagen: World Health Organization, on behalf of the European Observatory on Health Systems and Policies; 2008. p. 109.

13. Meneu R. Health Technology Assessment and Health Policy Today: A Multifaceted View of their Unstable Crossroads. In: del Llano-Señarís JE, Campillo-Artero C, editors. Health Technology Assessment and Health Policy Today: A Multifaceted View of their Unstable Crossroads [Internet]. Cham: Springer International Publishing; 2015. p. 37-49.

14. Schumacher I, Zechmeister I. Assessing the Impact of Health Technology Assessment on the Austrian Healthcare System. Int J Technol Assess Health Care. 2013;29(1):84-91.

15. Guthrie S, Bienkowska-Gibbs T, Manville C, Pollitt A, Kirtley A, Wooding S. The impact of the National Institute for Health Research Health Technology Assessment programme, 2003-13: A multimethod evaluation. Health Technol Assess. 2015;19(67):1-291. 
16. Wilsdon T, Serota A. A comparative analysis of the role and impact of Health Technology Assessment. London: Charles River Associates. 2011. [cited 2016 mar 15] Available from: http://www.efpia.eu/uploads/Modules/Documents/hta-comparison-report-updated-july-26-2011-stc.pdf

17. Jacob R, McGregor M. Assessing the impact of health technology assessment. Int J Technol Assess Health Care. Cambridge Univ Press; 1997;13(1):68-80.

18. McGregor M. What decision-makers want and what they have been getting. Value Heal. 2006;9(3):181-5.

19. Zechmeister I, Schumacher I. The Impact of Health Technology Assessment Reports on Decision Making in Austria. Int J Technol Assess Health Care. 2012;28(1):77-84.

20. Wild C, Patera N, Stricka M, Karnickas L. Background Analysis for National HTA Strategy for Lithuania Focus on Medical Devices. Vienna: Ludwig Boltzmann Institute; 2015.

21. Fakultní nemocnice Plzeň. Roční zpráva za rok 2014 [Internet]. 2015 [cited 2016 Mar 31]. Available from: https://www.fnplzen.cz/sites/default/files/dokumenty/rocni_zpravy/2014.pdf

22. Weiss C. The Many Meanings of Research Utilization. Public Adm Rev. 1979;39(5):426-31.

23. Drummond MF, Schwartz JS, Jönsson B, Luce BR, Neumann PJ, Siebert U, et al. Key principles for the improved conduct of health technology assessments for resource allocation decisions. Int $\mathbf{J}$ Technol Assess Health Care. 2008;24(3):244-58-8.

24. Smith K. Beyond evidence based policy in public health: the interplay of ideas. 2013.

25. Pollitt C, Talbot C, Caulfield J, Smullen A. Agencies. How Governments do Things Through Semi-Autonomous Organizations. Basingstoke, UK: Palgrave Macmillan; 2004.

26. Lindblom CE. The Science of "Muddling Through." Public Adm Rev. JSTOR; 1959;19(2):7988.

27. Andrews M. Good government means different things in different countries. Governance. 2010;23(1):7-35.

28. Daniels N, Sabin J. The ethics of accountability in managed care reform. Health Aff. 1998 Sep 1;17(5):50-64.

29. Daniels N, van der Wilt GJ. Health Technology Assessment, Deliberative Process, and Ethically Contested Issues. Int J Technol Assess Health Care. 2016;32(1-2):10-5.

30. World Health Assembly. Resolution WHA67.23: Health intervention and technology assessment in support of universal health coverage. 2014 p. 1-5. 